\title{
CHARACTERISTICS OF A CONTINUOUS HAZE PROCESS IN THE CHANG-ZHU-TAN REGION OF CHINA AND ITS INFLUENCING FACTORS
}

\author{
ZHU, Y. F. ${ }^{1,2}-$ GAO, J. ${ }^{1}-$ LIAO, J. Y. ${ }^{3 *}$ \\ ${ }^{1}$ College of Science, Central South University of Forestry and Technology, Changsha 410004, \\ China \\ ${ }^{2}$ Key Laboratory for Digital Dongting Lake Basin of Hunan Province, Changsha 410004, China \\ ${ }^{3}$ Hunan Forest Botanical Garden, Changsha 410116, China \\ *Corresponding author \\ e-mail: liaojuyang@163.com
}

(Received $17^{\text {th }}$ Jun 2019; accepted $16^{\text {th }}$ Oct 2019)

\begin{abstract}
Based on the surface meteorological observation data collected by meteorological stations 57687 (Changsha), 57773 (Xiangtan) and 57780 (Zhuzhou) of Hunan province from January 14 to 20, in 2017, and the air monitoring data of Changsha City, Zhuzhou City and Xiangtan City provided by The National Environment Monitoring Station, this paper analyzed the stage characteristics of a continuous haze process in the Chang-Zhu-Tan Region of China and its influencing factors in late January of 2017. The results show that the haze process has stage characteristics with the fog and the haze alternating. Through correlation analysis, it is concluded that PM2.5 concentration, vapor pressure of water, dew point temperature and relative humidity are the four key factors determining visibility. Through analyzing main components, a meteorological factor consisting of vapor pressure of water, dew point temperature and relative humidity is established. A linear model featuring PM2.5 concentrations and visibility and a cubic curve model featuring the meteorological factor and visibility are set up. During the continuous haze process, the average concentration of PM2.5 is greater than $88 \mathrm{ug} / \mathrm{m}^{3}$ and is inversely related to the visibility. Accumulation of highly concentrated PM2.5 causes low visibility. With the changes of humidity and dew point temperature, fog and haze appear alternatively.
\end{abstract}

Keywords: PM2.5 concentration, meteorological factors, visibility, Chang-Zhu-Tan Region

\section{Introduction}

With the rapid development of urban construction, industry and transportation in Changsha, Zhuzhou and Xiangtan (Chang-Zhu-Tan), the increase in the concentration of fine particles such as pollutants and dust in the near-surface layer has led to a decrease in visibility and more severe urban air pollution. Haze weather has become a danger to our living environment and the atmosphere. Major disasters have had serious negative impacts on the environment, health, climate, and economy. Foreign scholars have long been studying the climate characteristics of haze and its impact on regional climate. Elias et al. (2009) studied the effects of particles (smoke and fog) on visible light radiation. Jansen (2014) used the hourly measurement method to explore the role of secondary inorganic aerosols in Particulate Matter 2.5 (PM2.5) in the haze in Hangzhou, China.

Singh and Giri (2011) studied the properties of the interannual changes of fog and smoke and their impact on agricultural production. Domestically, Guo et al. (2015) analyzed the durative heavy fog weather such as aerosols, cloud condensation nuclei $(\mathrm{CCN})$, fog droplets spectrum and micro physical characteristics such as moisture 
content, atmospheric visibility and vertical structure characteristics of boundary layer. They explored the characteristics and mechanism of the formation, evolution and transformation of haze weather. Xie et al. (2015) analyzed the meteorological elements, PM2.5 concentration and atmospheric boundary layer characteristics of a large-scale continuous heavy haze process in central and eastern China, and concluded that PM2.5 concentration is inversely related to visibility and relative humidity. $\mathrm{Hu}$ et al. (2013) analyzed the characteristics and influencing factors of haze weather in Xi'an area by using the data from Xi'an meteorological station gathered since its establishment. Zhao et al. (2013) studied the characteristics of PM2.5 pollution on Beijing's autumn smoggy days using observation data such as PM2.5 concentration in Beijing's urban and suburban areas in 2011. Li et al. (2017) studied the causes and hazards of urban haze. Sun (2016) and Liu et al. (2013) analyzed the causes of continuous haze weather from the optical perspective. Zhu et al. (2015), Dai and Cheng (2008), Yin et al. (2014) Morones Esquivel et al. (2017) and Hou et al. (2017) all studied the meteorological causes of persistent haze.

At present, the domestic research on smog is mainly concentrated on the weather in the Beijing-Tianjin-Hebei region, Yangtze River delta, the Pearl River delta and other regions, though there are also some researches on the haze weather in Hunan province some other cities. For example, Yuan et al. (2015) and Leura Vicencio et al. (2017) analyzed daily visibility and relative humidity data from 1970 to 2012 of 76 ground meteorological observation stations, and obtained the daily fog and haze conditions in various regions of Hunan, using linear trend to analyze the characteristics of fog and haze years; Zhang et al. (2014) used the meteorological observation data and environmental monitoring data of the Changsha area from 1970 to 2012 to analyze the characteristics and influencing factors of smog in Changsha area over the past 43 years, but an analysis on the cause of the continuous smog process in Chang-Zhu-Tan region has not been reported. In this paper, hourly meteorological and environmental data from January 14 to 20, 2017 are used to study the occurrence and evolution of a persistent haze process in Chang-Zhu-Tan region, and corresponding mathematical models are established based on the influencing factors. The conclusion can provide a strong theoretical basis for optimizing environmental management and preventing haze scientifically in Chang-Zhu-Tan region.

\section{Materials and methods}

The research site, Chang-Zhu-Tan region, is located in the central and eastern part of Hunan Province in China, as shown in Figure 1. It is an important part of the urban agglomeration in the middle reaches of the Yangtze River, including Changsha, Zhuzhou and Xiangtan cities.

The conventional meteorological data used in this paper comes from the China Meteorological Data Network, which mainly includes ground and high-altitude data from January 14 to January 20, 2017 in Changsha, Zhuzhou and Xiangtan of China. The ground data includes air pressure, visibility, temperature, dew point temperature, and relative Humidity, wind direction and wind speed. Except dew-point temperature, all data is hourly data. Visibility data is obtained by referring to the method of obtaining visibility data in the paper (Cao et al., 2013). The altitude data are from the altitude data of Ma-Po-Ling station once a day (12 o'clock). The air pollutant data are from the environmental quality monitoring station, mainly including Particulate Matter 2.5 
(PM2.5) and Air Quality Index (AQI) data of the three cities of Chang-Zhu-Tan region, all of which are hourly average data.

Based on the meteorological and environmental data of Changsha-ZhuzhouXiangtan, this paper analyzes the internal relations among the influencing factors by correlation analysis, principal component analysis and regression analysis, and establishes the corresponding mathematical model.

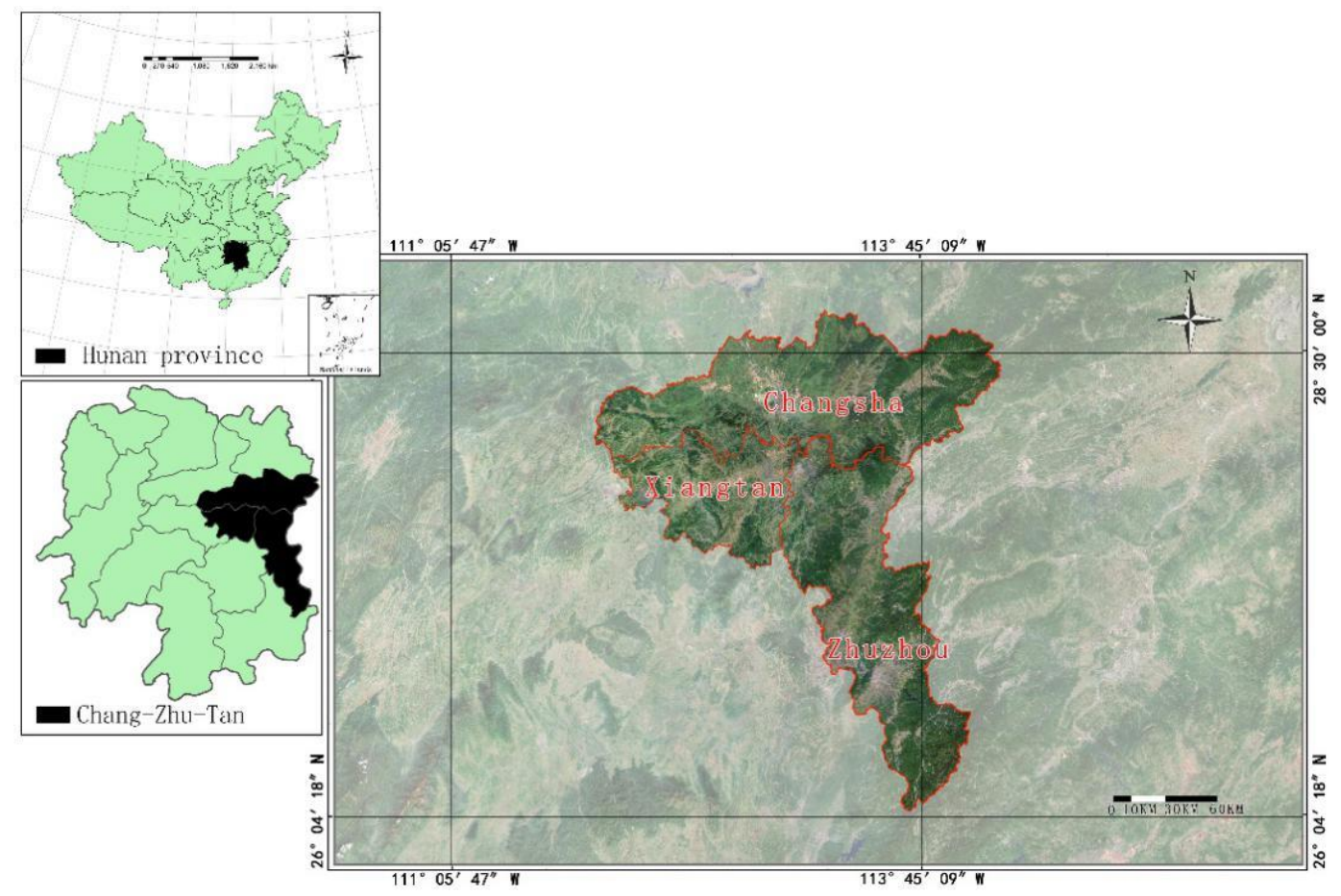

Figure 1. Location of research site

\section{Results}

\section{Process analysis}

\section{Air quality changes in Chang-Zhu-Tan region}

Chang-Zhu-Tan metropolitan area is the demonstration zone of the construction of "two-oriented society" and the core growth pole of Hunan province's economic development. Industrialization has accelerated in recent years, and environmental pollution has followed. During this haze, the average AQI and PM2.5 concentrations in Zhuzhou are the highest, respectively, 133 and $101 \mathrm{ug} / \mathrm{m}^{3}$. The average AQI and PM2.5 concentrations of Changsha are 112 and $87 \mathrm{ug} / \mathrm{m}^{3}$, respectively. The lowest is Xiangtan city, with average AQI and PM2.5 concentrations of 106 and $80 \mathrm{ug} / \mathrm{m}^{3}$, respectively. The AQI and PM2.5 concentrations in the three cities all reach peak in the afternoon of the $17 \mathrm{th}$. The changes of AQI and PM2.5 concentration are shown in Figure 2.

According to the air quality standards uniformly regulated by the State Environmental Protection Administration, Zhuzhou City has $43 \mathrm{~h}$ of moderate pollution and $107 \mathrm{~h}$ of light pollution. Changsha has $115 \mathrm{~h}$ of light pollution and above. Xiangtan city has $95 \mathrm{~h}$ of light pollution and above. The pollution is most serious in Zhuzhou City. 

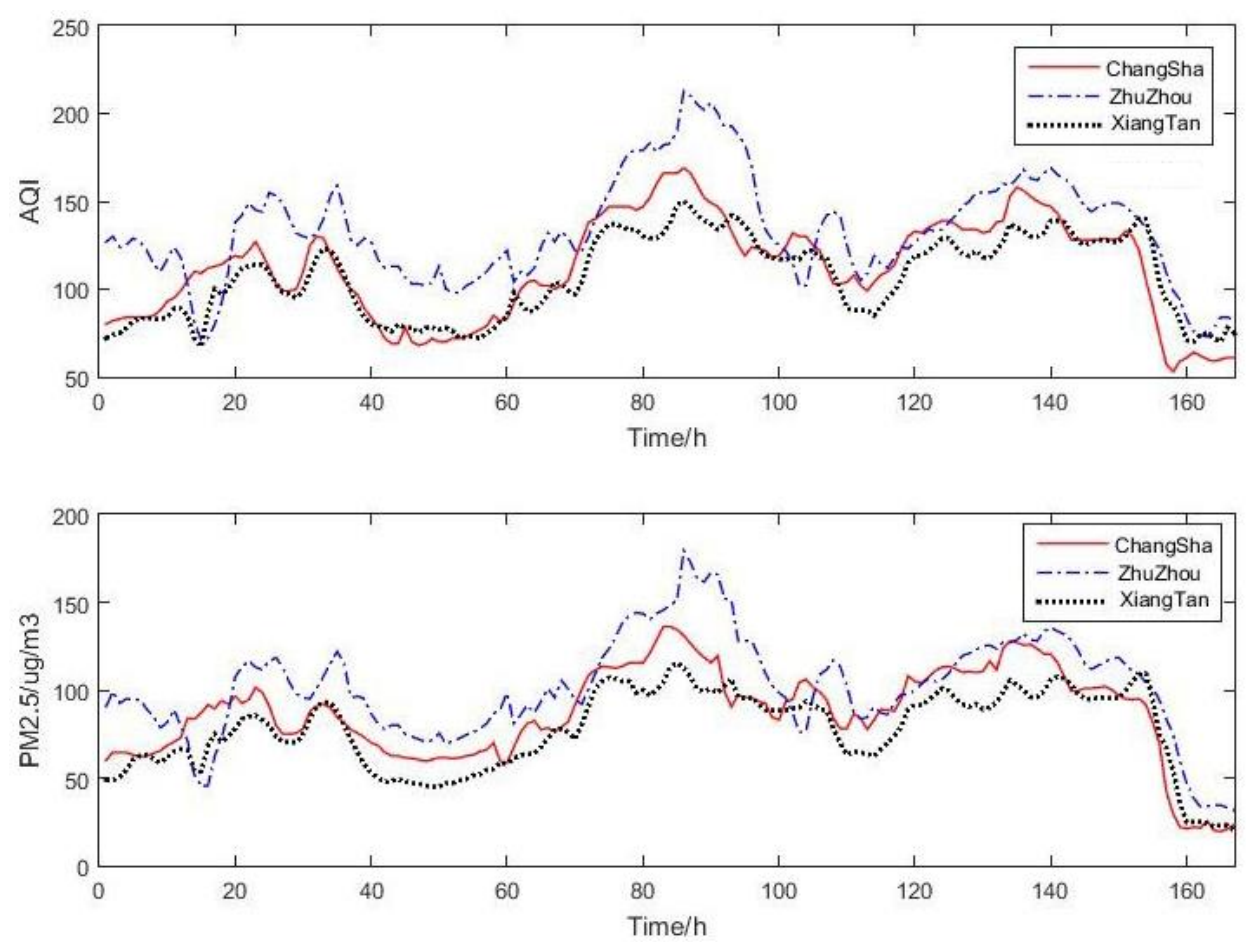

Figure 2. Variation of AQI and PM2.5 concentration in Chang-Zhu-Tan region

\section{Evolution of ground visibility}

During the smog process from January 14 to 20, 2017, the visibility is less than $1000 \mathrm{~m}$. The visibility is less than $800 \mathrm{~m}$ in nearly $136 \mathrm{~h}$, and the visibility is less than $500 \mathrm{~m}$ in $20 \mathrm{~h}$. The dense fog process with visibility less than $500 \mathrm{~m}$ is $4 \mathrm{~h}$. The minimum visibility of the haze process is $294 \mathrm{~m}$, as shown in Figure 3.

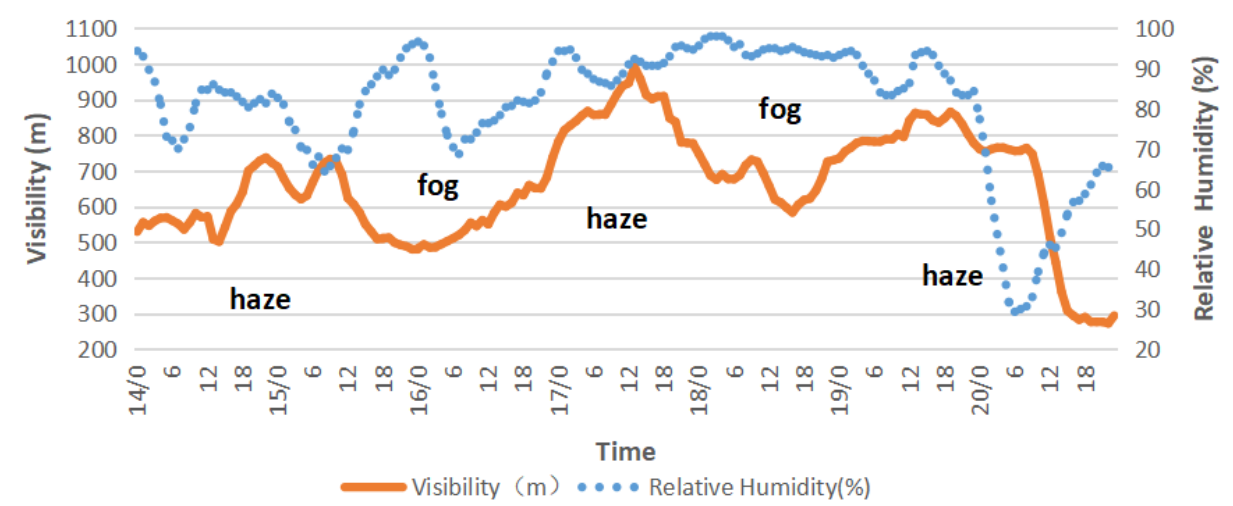

Figure 3. Variation trend of visibility and relative humidity

As shown in Figure 3, during the haze weather, many transitions and alternations between fog and haze occurred. According to the new haze standards issued by the China Meteorological Administration, atmospheric turbidity with a relative humidity greater than $95 \%$ is defined as fog, and atmospheric turbidity with a relative humidity less than $95 \%$ is defined as haze. According to the different visibility of haze weather, it is divided into four grades (Xie et al., 2015; Table 1). 
Table 1. Classification of haze levels

\begin{tabular}{c|c|c|c|c}
\hline Visibility $(\mathrm{km})$ & {$[5,10)$} & {$[3,5)$} & {$[1,3)$} & {$[0,1)$} \\
\hline Haze levels & Slight haze & Mild haze & Moderate haze & Heavy haze \\
\hline
\end{tabular}

According to this standard, the haze process in Chang-Zhu-Tan region is divided into five stages. The first, the third and the fifth stages are haze, and the second and fourth stages are fog.

\section{Changes in ground meteorological elements}

According to the collected ground meteorological data, the variation trend chart of wind direction, wind speed, maximum temperature, minimum temperature, visibility, relative humidity and dew point temperature is drawn, and the results are shown in Figure 4.
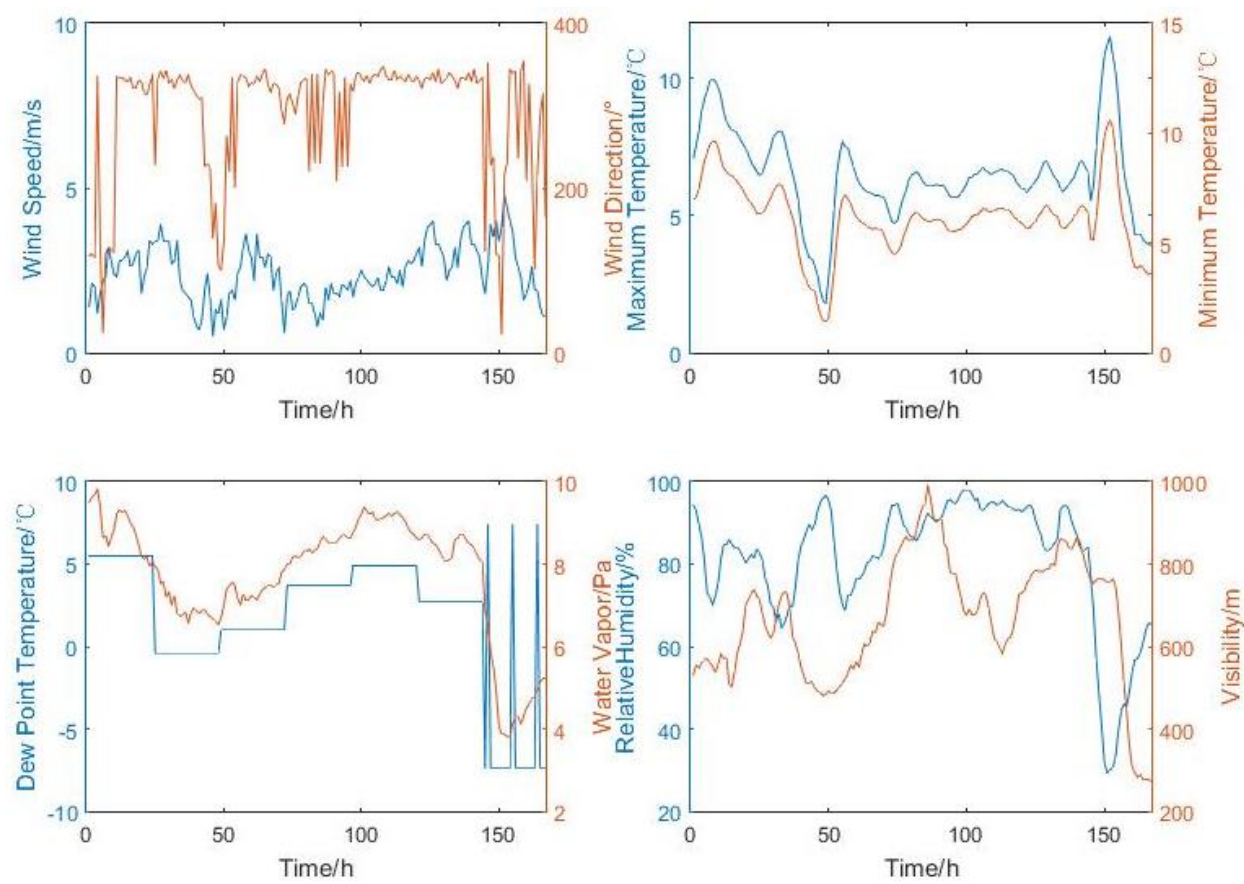

Figure 4. The trend chart of meteorological factors

The changes in meteorological elements near the surface of the continuous smog process in Changsha, Zhuzhou and Xiangtan are relatively obvious. The relative humidity increases with the decrease of the dew point and the temperature drop at night, which is conducive for the water vapor to condense to form fog; during the daytime, the opposite is true. In the second and fourth stages, the ground relative humidity increases to more than $95 \%$, corresponding to fog (Torres-Martinez et al., 2017). When relative humidity decreases, fog turns to haze. It can be seen that the increase of relative humidity is conducive to the increase of the hygroscopic growth of aerosol particles suspended in the air. When the air reaches a saturated state, haze will change into fog. As can be seen from the changes in wind speed, the wind speed during the haze is less than $4.8 \mathrm{~m} / \mathrm{s}$, and the wind speed during the fog process is mostly between $1.5 \mathrm{~m}$ and

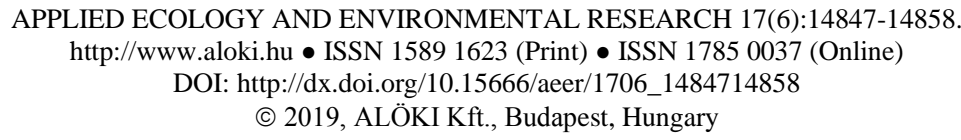


$2.5 \mathrm{~m} / \mathrm{s}$. In the process of haze occurrence, the wind speed is larger than that of fog, and the wind speed is between $2 \mathrm{~m} / \mathrm{s}$ and $4.8 \mathrm{~m} / \mathrm{s}$ (Bremer Bremer et al., 2016). It can be seen from the change of wind direction that when fog occurs, it is mostly southerly wind. When haze occurs, the wind direction is mainly north wind and northwest wind.

\section{Analysis of factors influencing visibility in haze weather process}

Visibility is closely related to ground meteorological elements and aerosol concentration in haze weather. In order to determine the main factors that influence the fog haze weather process at different stages, air pressure, wind direction, wind speed, temperature, dew point temperature, vapor pressure, relative humidity, the visibility and PM2.5 concentrations in this haze process are analyzed by Statistical Product and Service Solutions (SPSS) through Pearson correlation analysis on both sides. Pearson correlation coefficient formulas as shown in Equation 1. The correlation results are shown in Table 2.

$$
r=\frac{\sum_{i=1}^{n}\left(x_{i}-\bar{x}\right)\left(y_{i}-\bar{y}\right)}{\sum_{i=1}^{n}\left(x_{i}-\bar{x}\right)^{2} \sum_{i=1}^{n}\left(y_{i}-\bar{y}\right)^{2}}
$$

Table 2. Correlation analysis of visibility and influence factors

\begin{tabular}{c|c|c|c|c|c|c|c|c|c}
\hline \multicolumn{2}{l|}{} & $\begin{array}{c}\text { Air } \\
\text { pressure }\end{array}$ & $\begin{array}{c}\text { Wind } \\
\text { direction }\end{array}$ & $\begin{array}{c}\text { Wind } \\
\text { speed }\end{array}$ & Temperature & $\begin{array}{c}\text { Dew point } \\
\text { temperature }\end{array}$ & $\begin{array}{c}\text { Vapor } \\
\text { pressure }\end{array}$ & $\begin{array}{c}\text { Relative } \\
\text { humidity }\end{array}$ & PM2.5 \\
\hline \multirow{2}{*}{ vis } & Correlation & -0.020 & $0.274^{* *}$ & $0.222^{* *}$ & $0.269^{* *}$ & $0.352^{* *}$ & $0.400^{* *}$ & $0.293^{* *}$ & $1.000^{* * *}$ \\
& Significance & 0.799 & 0.000 & 0.004 & 0.000 & 0.000 & 0.000 & 0.000 & 0.000 \\
\hline
\end{tabular}

**Significantly correlated at 0.01 level (bilateral)

It can be seen from Table 2 that in addition to the air pressure, the visibility is strongly correlated with wind direction, wind speed, temperature, dew point temperature, vapor pressure, relative humidity, the visibility and concentrations of PM2.5 are strong correlation, and the correlation is confirmed at $99 \%$ by reliability test. Since the average wind speed during the whole haze weather is about $2.4 \mathrm{~m} / \mathrm{s}$, the wind speed provides a relatively stable weather background that enables small horizontal transportation, reflecting the consistency of wind speed and visibility on the weather scale. In comparison, PM2.5 concentration, vapor pressure of water, dew point temperature and relative humidity are more closely related to visibility, with correlation coefficients of $1.00,0.400,0.352$ and 0.293 respectively (Perez-Sicairos et al., 2016). It indicates that PM2.5 concentration, vapor pressure of water, dew point temperature and relative humidity are the four main factors that directly affect the visibility level during the haze.

\section{Establishment of relationship model between visibility and major factors}

Correlation analysis is conducted on PM2.5 concentration, vapor pressure of water, dew point temperature and relative humidity, and the results are shown in Table 2. It can be seen from the table that dew point temperature, vapor pressure of water, relative humidity and visibility have strong correlation, and passed the $99 \%$ confidence interval. 
In order to study the main factors affecting the visibility and avoid the overlapping effects among the factors, the correlation analysis of the influencing factors is conducted. The results are shown in Table 3.

Table 3. Correlation analysis of influencing factors

\begin{tabular}{c|c|c|c|c|c}
\hline \multicolumn{2}{c|}{ Control variables } & $\begin{array}{c}\text { The dew point } \\
\text { temperature }\end{array}$ & $\begin{array}{c}\text { Vapor } \\
\text { pressure }\end{array}$ & $\begin{array}{c}\text { Relative } \\
\text { humidity }\end{array}$ & PM2.5 \\
\hline \multirow{2}{*}{ The dew point temperature } & Correlation & 1.000 & 0.834 & 0.687 & 0.000 \\
& Significance (bilateral) & & 0.000 & 0.000 & 1.000 \\
\hline \multirow{2}{*}{ Vapor pressure } & Correlation & 0.834 & 1.000 & 0.841 & 0.000 \\
& Significance (bilateral) & 0.000 & & 0.000 & 1.000 \\
\hline \multirow{2}{*}{ Relative humidity } & Correlation & 0.687 & 0.841 & 1.000 & 0.000 \\
& Significance (bilateral) & 0.000 & 0.000 & & 1.000 \\
\hline \multirow{2}{*}{ PM2.5 } & Correlation & 0.000 & 0.000 & 0.000 & 1.000 \\
& Significance (bilateral) & 1.000 & 1.000 & 1.000 & \\
\hline
\end{tabular}

It can be seen from Table 3 that there is a strong correlation between dew point temperature, vapor pressure of water and relative humidity. Therefore, correlation analysis is conducted again on dew point temperature, vapor pressure of water and relative humidity, and correlation matrix $\mathrm{A}$ is obtained. Kaiser-Meyer-Olkin (KMO) and Bartlett tests are carried out, and the results are shown in Table 4.

$$
A=\left[\begin{array}{lll}
1.000 & 0.856 & 0.718 \\
0.856 & 1.000 & 0.854 \\
0.718 & 0.854 & 1.000
\end{array}\right]
$$

Table 4. KMO and Bartlett inspection

\begin{tabular}{l|c|c}
\hline \multicolumn{2}{c|}{ Sample enough Kaiser-Meyer-Olkin } & 0.688 \\
\hline \multirow{3}{*}{ Bartlett's sphericity test } & Approximate chi-square & 434.334 \\
& $\mathrm{df}$ & 3 \\
& Sig. & 0.000 \\
\hline
\end{tabular}

From Table 4, the KMO test coefficient is $0.688>0.5$, and the data have structural validity above $99 \%$ confidence interval, so dew point temperature, vapor pressure of water and relative humidity can be used for the principal component analysis. Through principal component analysis, the results are shown in Table 5.

As shown in Table 5, the cumulative percentage of dew point temperature, vapor pressure of water and relative humidity is $100 \%$. Therefore, dew point temperature, vapor pressure of water and relative humidity can be aggregated into a meteorological factor. As for the component score coefficient matrix, the dew point temperature is 0.350 , the vapor pressure is 0.369 , the relative humidity is 0.350 . Through the score matrix the weight of each factor is calculated, and they are $0.327,0.345,0.327$, respectively. If the meteorological factor is $\mathrm{f}$, the dew point temperature, vapor pressure of water and relative humidity are $\mathrm{x} 1, \mathrm{x} 2$ and $\mathrm{x} 3$ respectively, then Equation 2 is satisfied. 


$$
f=0.327 x_{1}+0.345 x_{2}+0.327 x_{3}
$$

Table 5. Principal component analysis of influencing factors

\begin{tabular}{c|c|c|c|c|c|c}
\hline \multirow{2}{*}{ Component } & \multicolumn{3}{|c|}{ Initial eigenvalue } & \multicolumn{3}{c}{ Extract the squares and load } \\
\cline { 2 - 7 } & Summation & Variance's \% & Accumulation \% & Summation & Variance's \% & Accumulation \% \\
\hline 1 & 2.620 & 87.345 & 87.345 & 2.620 & 87.345 & 87.345 \\
2 & 0.282 & 9.404 & 96.749 & & & \\
3 & 0.098 & 3.251 & 100.000 & & & \\
\hline
\end{tabular}

\section{Model prediction}

Meteorological factors and PM2.5 concentration are the main factors affecting visibility. In order to explore the objective relationship between meteorological factors and visibility and that between PM2.5 concentration and visibility, two models are established. First, the model with the highest fitting degree is found through curve fitting. The result is shown in Figure 5.

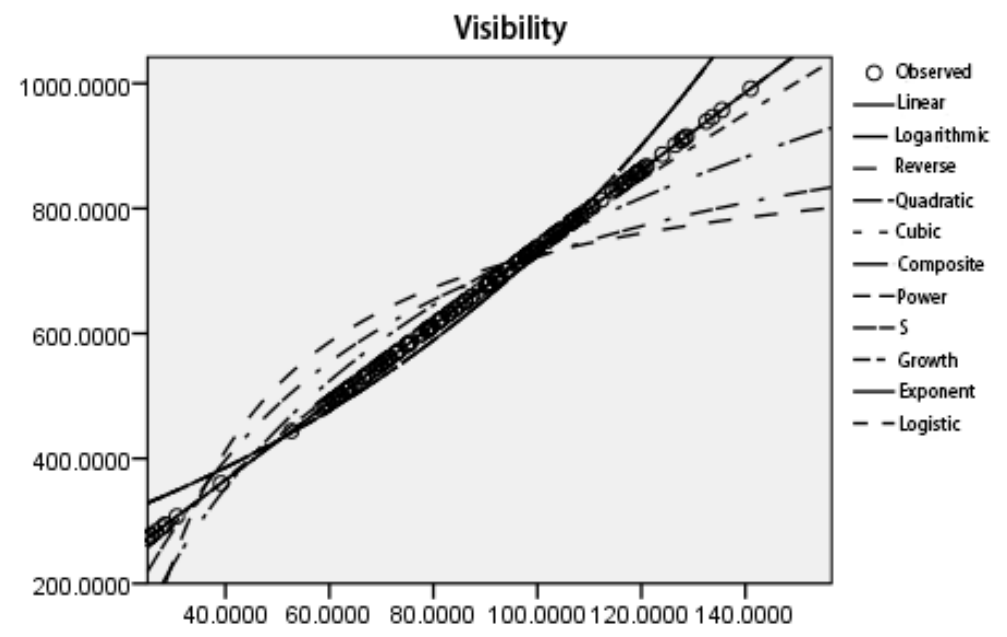

PM2.5

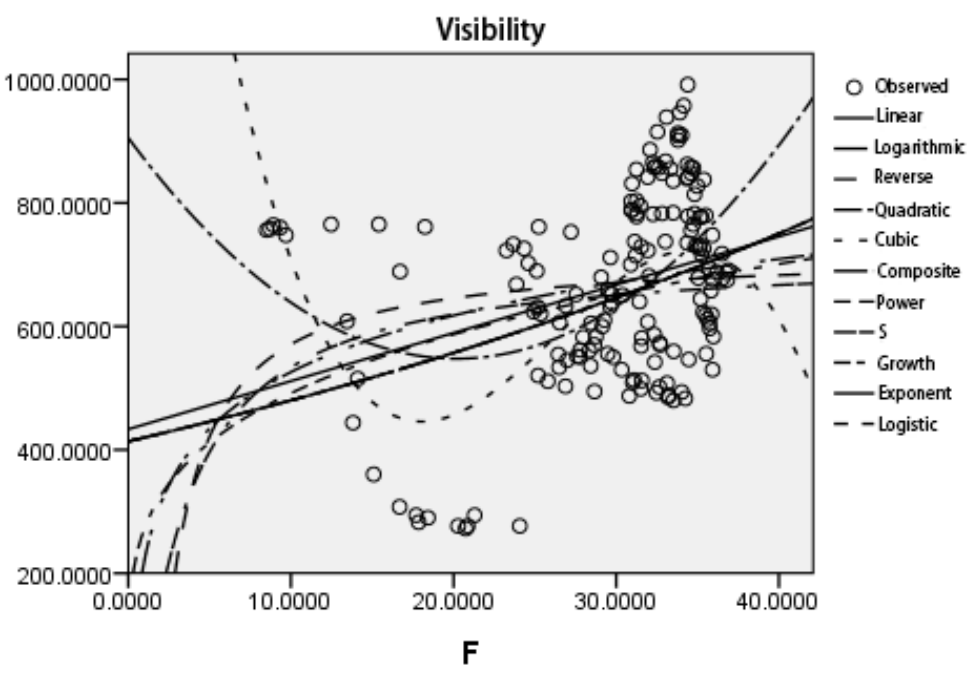

Figure 5. Model curve estimation

APPLIED ECOLOGY AND ENVIRONMENTAL RESEARCH 17(6):14847-14858. http://www.aloki.hu • ISSN 15891623 (Print) • ISSN 17850037 (Online)

DOI: http://dx.doi.org/10.15666/aeer/1706_1484714858 (C) 2019, ALÖKI Kft., Budapest, Hungary 
As can be seen from Figure 5, the relationship between PM2.5 concentration and visibility fits the linear model best. The relationship between meteorological factor $\mathrm{F}$ and visibility fits the three models best. Therefore, visibility is set as V (m), PM2.5 concentration is $\mathrm{P}\left(\mathrm{ug} / \mathrm{m}^{3}\right)$, and meteorological factor is $\mathrm{F}$. The linear model between PM2.5 concentration and visibility, and the cubic model between meteorological factors and visibility are respectively established.

\section{Model establishment}

Establishment of a linear model between PM2.5 concentration and visibility

(1) Regression analysis

It can be seen from Figure 5 that of the relationship between PM2.5 concentration and visibility fits the linear model best, so the linear model is established. The results of linear regression analysis of PM2.5 concentration and visibility are shown in Table 6.

Table 6. PM2.5 concentration and visibility linear regression analysis

\begin{tabular}{c|c|c|c|c}
\hline & Coefficient & Standard error & Precision & Significance \\
\hline (Constant) & 117.400 & .000 & $7.974 \mathrm{E} 7$ & .000 \\
PM2.5 & 6.200 & .000 & $3.867 \mathrm{E} 8$ & .000 \\
\hline
\end{tabular}

The linear model between PM2.5 concentration and visibility is established by using the data in the table, as shown in Equation 3.

$$
v=6.2 p+117.4
$$

(2) Model test

The linear model between PM2.5 concentration and visibility is tested, as shown in Figures 6 and 7.

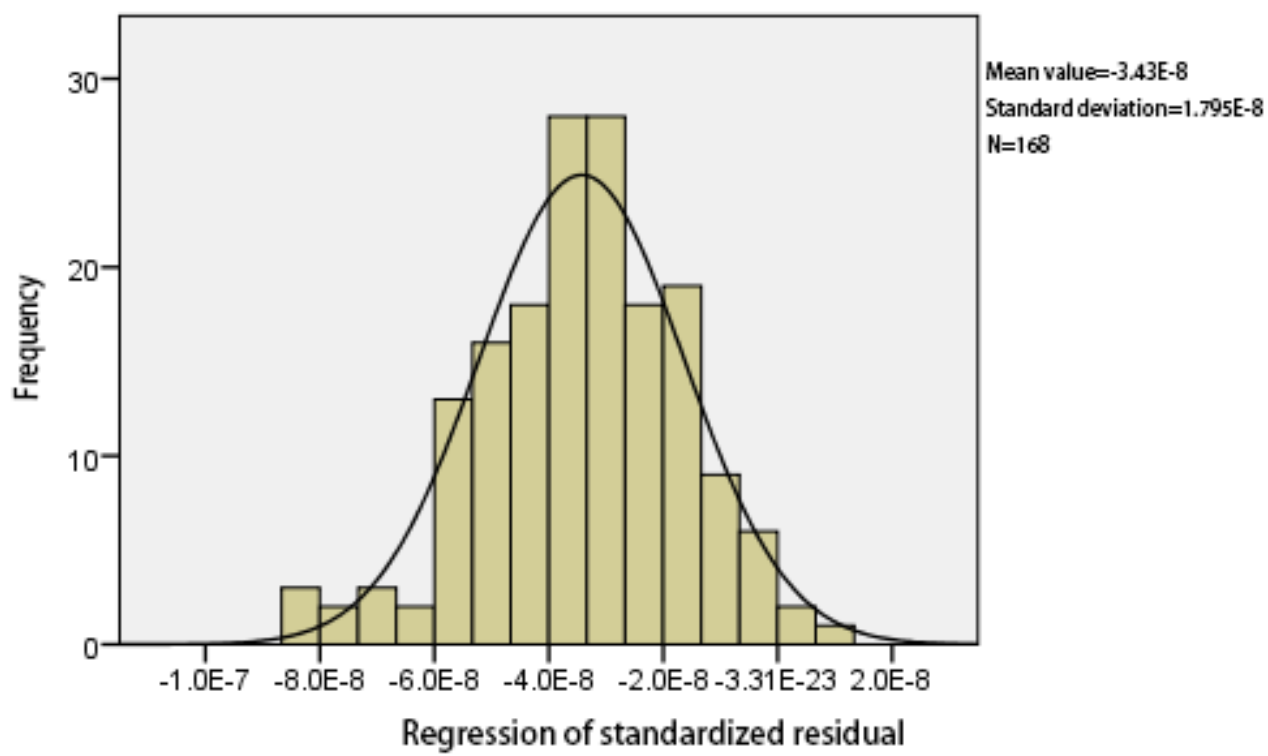

Figure 6. Visibility standard residual histogram 
It can be seen from Figure 6 that the distribution of standardized residual is basically normal distribution, so the resulting regression equation has practical significance.

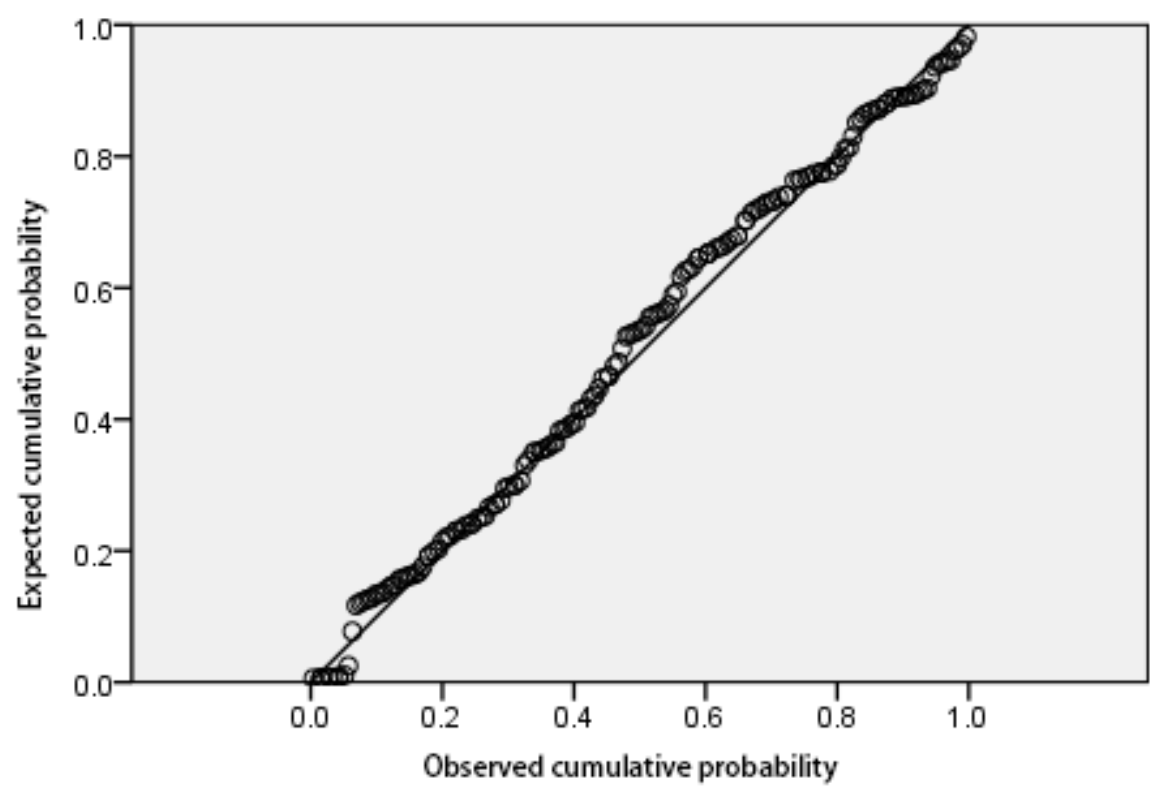

Figure 7. Visibility standard residual P-P diagram

It can be seen from Figure 7 that points in the figure can form approximately a straight line, so the data conforms to the specified distribution after verification.

Establishment of cubic model between meteorological factors and visibility

It can be seen from Figure 5 that the curve estimation of meteorological factors and visibility has the highest degree of fitting with the third-order model, so the cubic model is established. The results are shown in Table 7.

Table 7. Summary and parameter estimation of meteorological factors and visibility models

\begin{tabular}{c|c|c|c|c|c|c|c|c|c}
\hline \multirow{2}{*}{ Equation } & \multicolumn{4}{|c|}{ Model summary } & \multicolumn{4}{c}{ Estimate of parameter } \\
\cline { 2 - 11 } & $\mathbf{R}^{\mathbf{2}}$ & $\mathbf{F}$ & $\mathbf{d f 1}$ & $\mathbf{d f 2}$ & Sig. & Constant & b1 & b2 & b3 \\
\hline Cubic & 0.288 & 22.089 & 3 & 164 & 0.000 & 2169.164 & -231.267 & 9.755 & -0.124 \\
\hline
\end{tabular}

From the data in Table 6 it can be seen that the fitting degree of the model is 0.288 and the confidence interval of more than $99 \%$ passes. Therefore, the three-order curve model between meteorological factors and visibility is established as shown in Equation 4.

$$
v=-231.267 f^{3}+9.755 f^{2}-0.124 f+2169.164
$$

Description:

$f=0.327 x_{1}+0.345 x_{2}+0.327 x_{3}$ and $x_{1} x_{2} x_{3}$ denotes dew point temperature $\left({ }^{\circ} \mathrm{C}\right)$, vapor pressure of water (Bpa) and relative humidity (\%), respectively. 


\section{Discussion and conclusion}

(1) There are stage characteristics in this haze process. Although the time of haze occurrence is relatively short compared with that of haze occurrence, it still presents the phenomenon of haze and fog alternation.

(2) Low ground wind speed, rising PM2.5 concentration and fluctuation of relative humidity provide favorable conditions for the formation and development of haze weather alternation. PM2.5 concentration, vapor pressure of water, dew point temperature and relative humidity are four key factors that determine visibility.

(3) During the haze, PM2.5 concentration is linearly related to visibility, and meteorological factors formed by vapor pressure of water, dew point temperature and relative humidity are correlated with visibility in the cubic curve.

(4) In future studies, more factors such as wind direction and temperature will be considered to establish a more comprehensive mathematical model to predict trends in the ongoing smog process that may occur in the future.

Acknowledgments. The work was financially supported by Key Research \& Development Plan in Hunan (2017SK2272) and Hunan Forestry Science and Technology Plan (XLK201738).

\section{REFERENCES}

[1] Bremer Bremer, M. H., Lozano Garcia, D. F., Rodriguez Garcia, M., Hori Ochoa, M. D. C. (2016): Characterization of the pollution levels in a sulfur mine using high resolution satellite imagery to optimize the sampling plan. - Revista Internacional De Contaminacion Ambiental 32: 165-176.

[2] Cao, W. H., Liang, X. D., Li, Q. C. (2013): A study of the stageful characteristics and influencing factors of a long-lasting fog/haze event in Beijing. - Acta Meteorologica Sinica 71(5): 940-951.

[3] Dai, J., Cheng, Y. X. (2008): Analysis on the first haze weather process in Beijing in July 2016. - Environmental Science Guide 37(01): 34-41.

[4] Elias, T., Haeffelin, M., Drobinski, P., Gomes, L., Rangognio, J., Bergot, T., Chazette, P., Raut, J., Colomb, M. (2009): Particulate contribution to extinction of visible radiation: pollution, haze, and fog. - Atmospheric Research 92(4): 443-454.

[5] Guo, L. J., Guo, X. L., Gang, C. G., Zhu, S. C. (2015): Observation and analysis on the occurrence, evolution and transformation characteristics of a persistent severe haze weather in north China. - Scientia Sinica (Terrae) 45(4): 427-443.

[6] Hou, Y. H., Xu, F. S., Zhang, R., Zhao, M., Ming, H. Q. (2017): Analysis on the meteorological causes of persistent haze in a sub-region of Liaoning province. Meteorological Technology 45(04): 710-716.

[7] Hu, L., Cao, H. L., Zhang, W. J., Wang, Q., Mu, J. (2013): Characteristics of air quality change and its relationship with meteorological conditions in Xi'an city. - Journal of Meteorology and Environment 29(06): 150-153.

[8] Jansen, R. C., Shi, Y., Chen, J., Hu, Y., Xu, C., Hong, S., Li, J., Zhang, M. (2014): Using hourly measurements to explore the role of secondary inorganic aerosol in PM 2.5 during haze and fog in Hangzhou, China. - Advances in Atmospheric Sciences 31(6): 14271434.

[9] Leura Vicencio, A. K., Carrizales Yanez, L., Razo Soto, I. (2017): Mercury pollution assessment of mining wastes and soils from former silver amalgamation Area in NorthCentral Mexico. - Revista Internacional De Contaminacion Ambiental 33: 655-669. 
[10] Li, L. M., Li, L. G., Li, N. W. (2017): Research progress on the causes and hazards of urban smog. - Environmental Engineering 35(12): 92-97 + 104.

[11] Liu, H. M., Fang, C. L., Huang, J. J., Zhu, X. D., Zhou, Y., Wang, Z. B., Zhang, Q. (2013): Analysis on the spatial and temporal characteristics and influencing factors of air pollution in Beijing-Tianjin-Hebei area. - Journal of Geography 73(01): 177-191.

[12] Morones Esquivel, M. M., Pantoja Espinoza, J. C., Proal Najera, J. B., Chairez Hernandez, I., Gurrola Reyes, J. N., Avila Santos, M. (2017): Use of a plate reactor (TiO2/GLASS) for the degradation of 2,5-diclorofenol by solar photocatalisis. - Revista Internacional De Contaminacion Ambiental 33: 605-616.

[13] Perez-Sicairos, S., Alejandro Corrales-Lopez, K., Martin Hernandez-Calderon, O., Israel Salazar-Gastelum, M., Maria Felix-Navarro, R. (2016): Photochemical degradation of nitrobenzene by S2o8-2 ions and Uv radiation. - Revista Internacional De Contaminacion Ambiental 32: 227-236.

[14] Singh, J., Giri, R. K. (2011): Inter-Annual Variation of Fog, Mist, Haze and Smoke at Amritsar and Its Impact on Agricultural Production. - In: Attri, S. D. et al. (eds.) Challenges and Opportunities in Agrometeorology. Springer, Berlin, pp. 409-419.

[15] Sun, R. (2016): Analysis on the optical characteristics and cause of a persistent haze weather process. - The 33rd Annual Meeting of the Chinese Meteorological Society S10 City, Precipitation and Fog Haze - The Fifth City Meteorological BBS, Chinese Meteorological Society 14.

[16] Torres-Martinez, A., Sanchez, A. J., Alvarez-Pliego, N., Amalia Hernandez-Franyutti, A., Carlos Lopez-Hernandez, J., Bautista-Regil, J. (2017): Gonadal histopathology of fish from La Polvora Urban Lagoon in the Grijalva Basin, Mexico. - Revista Internacional De Contaminacion Ambiental 33: 713-717.

[17] Xie, Z. Z., Fan, X. L., Wang, Y. L., Zha, H. H., Wang, T. F., Sun, Y. (2015): Phase characteristics of a persistent fog and haze process and its influencing factors in Huaian area. - Journal of Meteorology and Environment 31(5): 79-85.

[18] Yin, C. M., Yu, L. J., Zhang, Y. J., Cai, Z., Gao, F. (2014): Analysis on characteristics of haze in Jinan City. - Population Resources and Environment in China 24(S3): 68-70.

[19] Yuan, Z. S., Chen, T., Xiao, L., Li, C. (2015): Analysis on characteristics of haze climate change in Hunan province in the last 43 years. - Journal of Disaster Prevention and Technology Institute (04).

[20] Zhang, X. H., Liu, L. Y., Chen, X. H. (2014): Analysis of haze characteristics and influencing factors in Changsha. - Journal of Environmental Engineering 8(08): 33613366.

[21] Zhao, X. J., Pu, W. W., Meng, W., Ma, Z. Q., Dong, F., He, D. (2013): Analysis on the optical characteristics of pollution and aerosol in autumn haze days in Beijing. Environmental Science 34(02): 416-423.

[22] Zhu, Y. Q., Hu, S. Q., Cao, Z. C. (2015): Analysis on the periodic causes of a persistent haze in Linyi City. - Journal of Environmental Engineering 9(12): 5979-5986. 